\title{
LIGHT-ADAPTED SPECTRAL SENSITIVITY OF THE GOLDFISH: A REFLEX MEASURE ${ }^{1}$
}

\author{
MALREEN K. POWERS \\ Department of Psychology. University of Michigan. Ann Arbor, MI 48109. U.S.A.
}

(Received 21 October 1977)

\begin{abstract}
Light-adapted spectral sensitivity of the goldfish was measured using the dorsal light reaction-the reflexive tendency of fish to tilt their dorsal surface toward bright light. Subjects were placed between two $150^{*}$ extended monochromatic fields, one of which was always $532 \mathrm{~nm}$. The angle of tilt toward or away from the $532 \mathrm{~nm}$ light was measured, and the relative intensities of the fields were adjusted until the fish did not tilt. Blind fish did not tilt at all, and fish without utricular otoliths tilted more than normal. The spectral sensitivity obtained using this method peaked near $600 \mathrm{~nm}$ and was shallow and broad. The results are similar to those of electrophysiological studies, but different from other behavioral studies.
\end{abstract}

Key Words-goldfish; spectral sensitivity; dorsal light reaction; retina.

\section{INTRODUCTION}

The cones in the retina of the goldfish contain three photopigments (Liebman and Entine, 1964; Marks, 1965; Hárosi and MacNichol, 1974; Marc and Sperling, 1976a.b; Stell and Hárosi, 1976). Although the relative spectral sensitivities of the cones match the absorption spectra of the photopigments (Tomita, Kaneko, Murakami and Pautler, 1967), the spectral sensitivities of other retinal neurons often do not (see, for example, Wagner, MacNichol and Wolbarsht, 1960; Witkowsky, 1965; Kaneko, 1973). The modification of spectral sensitivity proximal to the receptors is attributable to neural interactions within the retina. These interactions generally result in a narrowing of the band of wavelengths to which cells respond, so that few single neurons respond well throughout the range of wavelengths covered by the three photopigments.

Unlike single cells, gross potentials recorded in the goldfish's visual system are influenced by lights from every spectral region to which the pigments are sensitive. The spectral sensitivity curves of the isolated photoreceptor response Witkovsky, Nelson and Ripps, 1973), the ERG (Burkhardt, 1966, 1968; Regan, Schellart, Spekreijse and van den Berg, 1975) and the tectal evoked response (TER) (Regan et al., 1975) are typically very broad and flat with heightened sensitivity in the longer wavelengths.

The goldfish also responds behaviorally to stimuli throughout the range of sensitivity of its photopigments (Cronly-Dillon and Muntz, 1965; Yager, 1967 Shefner and Levine, 1976; Beauchamp and Rowe, 1977). But each attempt to measure behavioral spectral sensitivity has so far yielded a different function,

\footnotetext{
${ }^{1}$ Submitted in partial fulfillment of the requirements for the degree Doctor of Philosophy in Psychology at the University of Michigan. A summary of part of this work has appeared eisewhere (Powers, 1976).

Current address: Department of Psychology, NI-25. University of Washington, Seattle. Washington 98195 . U.S.A.
}

none of which matches what might be predicted from the electrophysiology.

This paper describes a behavioral measurement of photopic spectral sensitivity that closely matches recent electrophysiological recordings from both retina and optic tectum of the goldfish (Regan et al., 1975). I used the dorsal light reaction (DLR), which is a reflexive tendency of the fish to tilt about its longitudinal axis so that its dorsal surface is toward bright light. This reaction occurs in most teleosts (see Silver, 1974, for a brief review), and has been studied extensively by von Holst (e.g. 1935; for a review in English, see Pfeiffer, 1964), who found that the behavior results from an interaction between visual and vestibular systems.

\section{METHODS}

\section{Apparatus}

Figure IA shows the apparans. The fish was placed in a box flled with aerated water. Both tungsten sources $(120 \mathrm{~V}$ ac., $60 \mathrm{~W})$ received current via the same constantvoltage transformer (Sola Electric). Each noncollimated beam passed through heat, interference and spectrally calibrated neutral density filters (Optics Technology) beiore reaching a diffusing screen (white bond paper glued to the outside of the clear plastic box) next to the fish. The light energy at the plane of the fish's eye was measured at each wavelength with a calibrated photodiode (United Detector Technology PIN-IODF) whose response was constant $\pm 10 \%$ from $409 \mathrm{~nm}$ to $950 \mathrm{~nm}$ (Powers, 1977). At $532 \mathrm{~nm}$ the irradiance was $12.50 \log$ quanta/sec per $\mathrm{cm}^{2}$, which is about $8 \mathrm{log}$ units above absolute threshold for the gold. fish at this wavelength (Powers and Easter, 1978a). The half-bandwidths of the interference filters were $25-55 \mathrm{~nm}$. The stimulus fields were approximately square, and each subtended about $150^{\circ}$ of visual angle in width. (The actual subtense varied from $120^{\circ}$ to $170^{\circ}$, depending upon the fish's lateral position in the box.) The eye was near the center of the field. Cardboard baffles and black cloth minimized stray light, and the back, bottom and top of the fish's box were covered with opaque material during measurements. 

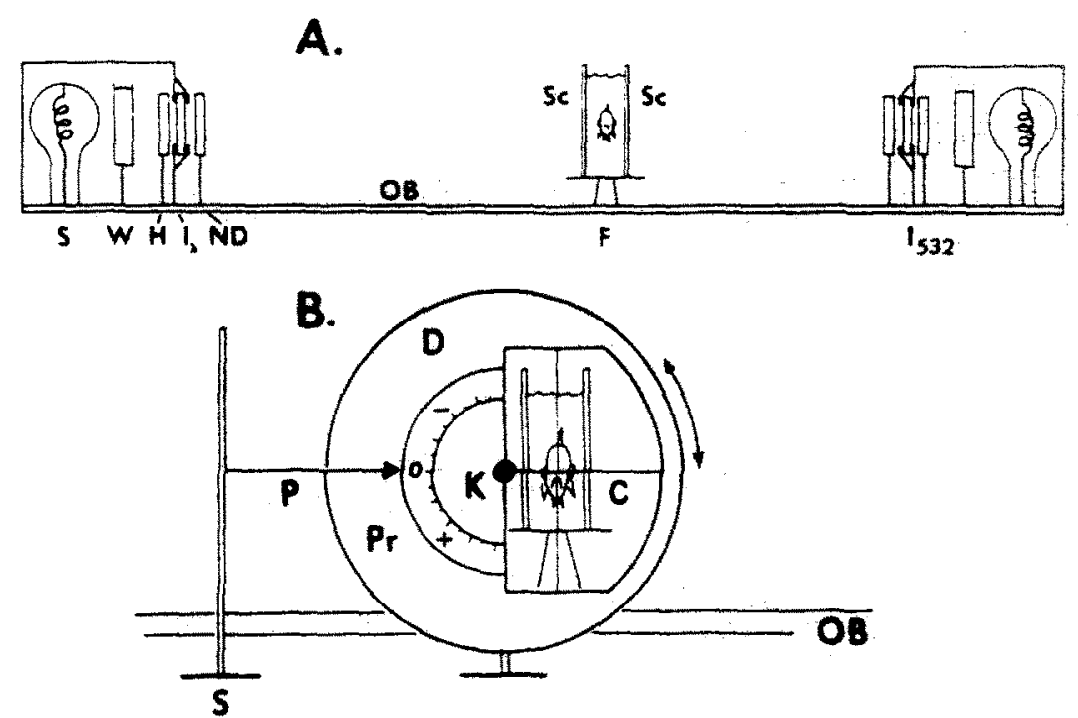

Fig. 1. DLR apparatus. A. Optical bench. The left and right ends of the bench were identical except for the wavelength of the interference filter in each. $O B$ : optical bench; $S$ : source; $W$ : water-filled heat filter; $H$ : glass heat filter; $I_{i} . I_{\$ 32}$ : interference fiters; $N D$ : neutral density filter(s); $F$; fish in box with aerated water; Sc: screens of bond paper. B. Measuring wheel. OB: opticat bench; D: cardboard disc: $S$ : stand: $\mathrm{K}$ : knob by which disc is rotated; $\mathrm{C}$ : crosshairs; $\mathrm{Pr}$ : protractor: $\mathrm{P}$ : pointer. See text for procedure.

The variation in emission of one of the lamps was monitored for 30 min with the calibrated photodiode, and found to vary about $\pm 10 \%$ around the mean, but because the current to both lamps went through the same regulated transformer, their relative intensities were assumed to be constant.

\section{Subjects}

Six goldfish (Carassius auratus: Ozark Fisheries. Stoutland. MOl. $12-14 \mathrm{~cm}$ in total body length. were subjects. They were kept in individual 5 gallon aquaria at a temperature of about $20^{\circ} \mathrm{C}$. Four subjects were unoperated. and were concurrently subjects in classical conditioning experiments reported elsewhere (Powers and Easter, 1978a.b). One subject was blind: both eyes had been removed 7 weeks before this experiment. The fish appeared healthy at the time the DLR measurements were made. Another fish had both utricular otoliths removed (see Powers, 1977, for details)

\section{Procedure}

Subjects were allowed sufficient time to become habituated to the test box $(10 \mathrm{~min}$ for experienced fish, longer for naive ones). The room lights were turned off during habituation and DLR measurements.

Figure $1 \mathrm{~B}$ illustrates the method of measurement. A protractor was mounted on a dise which could be rotated about its center. Part of the disc opposite the protractor was cut away so the fish could be seen behind it and crosshairs made of thin surgical silk were fixed in the open space. To make a measurement, the vertical crosshair was first aligned with two marks on the outside of the box (not visible in the figure) and a pointer was positioned at the horizontal $\left(0^{\circ}\right)$ mark on the protractor. Then the disc was turned until the crosshairs had the same orientation as the fish, with the vertical crosshair along the dorso-ventral body axis and the horizontal one through the pupils. It was necessary to wait until the fish was in a head-on position before making a measurement.

The number of degrees tilted toward $(t)$ or away from (-) a standard green light $(532 \mathrm{~nm}$; always in the right hand beam) was measured for each comparison filter. Then the beam toward: which the fish tilted was attenuated in approximately $0.3 \mathrm{log}$ unit steps until the fish tilted toward the other one. Fifteen measurements were made at each intensity; the mean time to complete measurentents for a given wavelength was $21 \mathrm{~min}$. For three of the normal fish the shorter wavelengths were tested first and for the fourth the longer were tested first. There were no system. atic variations in response due to order of testing.

The mean degrees of tilt at each intensity was calculated from the fiften measurements. and the intensity trelative to the $532 \mathrm{~nm}$ standard) at which the fish did not tilt was determined. When none of the relative intensities actually tested produced zero tilt, a linear interpolation was made between the two points on either size of the zero tilt line. The zero tilt values were used to construct the individual spectral sensitivities. relative to $532 \mathrm{~nm}$.

\section{RESULTS}

The DLR of a typical normal fish is shown in Fig. 2. The tilt is roughly linear with log intensity over the approximately $1 \mathrm{log}$ unit range examined. The slope is about $10^{\circ} / \log$ unit.

The otolithectomized fish showed qualitatively similar behavior, but the slope was about four times greater (Powers, 1977).

The blind fish did not tilt in response to light, even though the relative intensities of the two stimulus fields differed by 3.0 log units (Fig. 3). The response to different wavelength pairs was no greater than \pm 2 S.E.M. around the fish's babitual tilt in room illumination. This finding confirms that DLR results from stimulation of the eye.

Figure 4 shows the spectral sensitivity of the normal goldfish. The mean log intensity at zero tilt for the four fish has been corrected for absorption by the ocular media (Burkhardt, 1966), and plotted as an equal quantum spectrum (Dartnall, 1953). The peak is at $600 \mathrm{~nm}$, or slightly less.

The possibility that stray light or light beyond the nominal bandpass of the interference fitters caused the spectral sensitivity curves to be shallow was ruled out by determining the extrafoveal scotopic spectral sensitivity curve of a human observer (MKP) in the same optical setup (omitting the water). The curve 


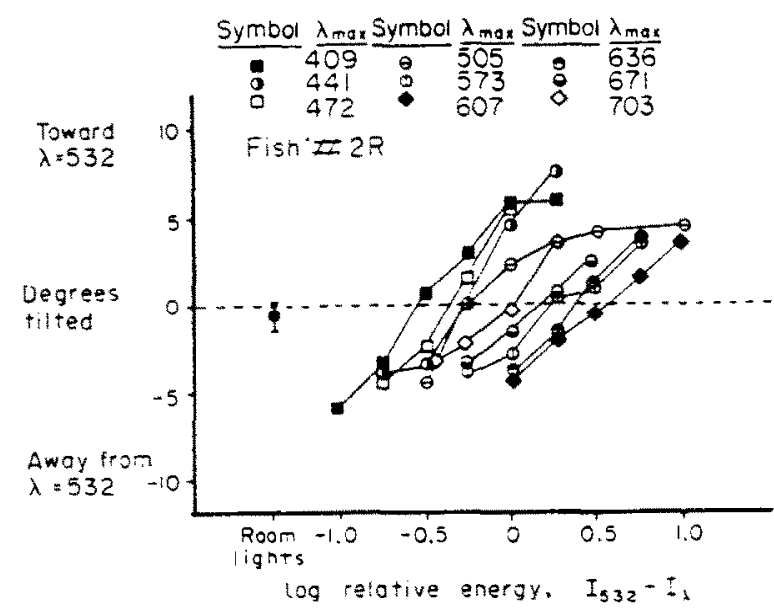

Fig. 2. DLR of a normal fish. Ordinate: number of degrees tilted toward $(+)$ or away from $(-)$ the standard $(532 \mathrm{~nm})$ light. Zero degrees tilted means the two lights were balanced in their effect on the fish. Abscissa: relative intensity of the standard and comparison lights. The filled circle on the left is the mean of 15 measurements with no differential monochromatic illumination: the room lights only were on. The bar indicates \pm IS.E.M. Different symbols represent different comparison wavelengths. Standard errors around these points ( 15 measurements each) averaged $\pm 0.49^{\circ}$

obtained matches that of the CIE standard observer (Powers. 1977). This result also implies that any spectral effects of sending noncollimated light through the interference filters must have been small.

\section{DISCLSSION}

DLR is a visually mediated behavior that is reflexive and easy to measure. The results show that the normal goldfish does tilt sufficiently to obtain an action spectrum. These experiments are not the first to demonstrate the usefulness of DLR in obtaining action spectra (cf. Thibault, 1949; Silver, 1974), but they are the first to do so in a fish whose physiology is well known. This makes direct comparisons between behavior and physiology possible.

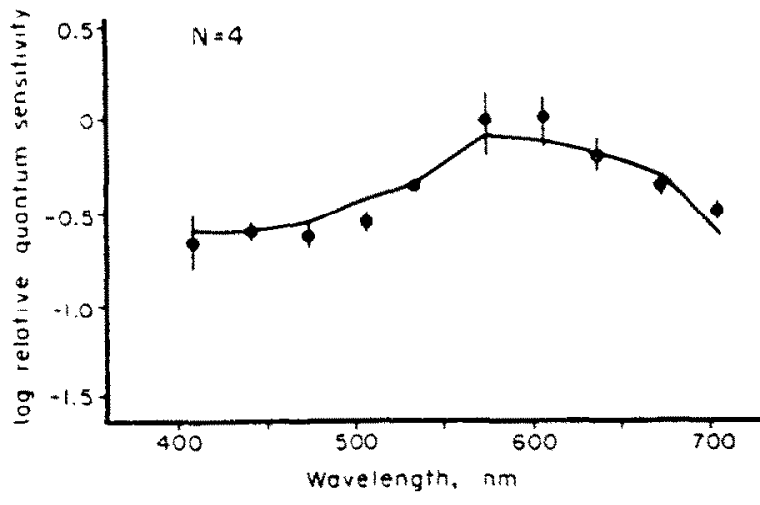

Fig. 4. Photopic spectral sensitivity of the normal goldfish. Points: mean log values for four fish. corrected for losses in the ocular media (Burkhardt. 1966). Bars \pm 1 S.E.M. Curve: best-fitting algebraic function derived from known spectral sensitivities of goldfish cones. See text for details.

\section{Relation to photopigments}

If the behaviorally measured sensitivity at any wavelength were determined by the single pigment that was maximally sensitive at that wavelength (an "envelope" model), then the spectral sensitivity curve should have as many maxima as there are pigments. On that basis the goldfish should have three, and the results in Fig. 4 do not support that prediction. However, an "additive" model, wherein the sensitivity at any wavelength is determined by some weighted combination of the sensitivities of all three pigments at that wavelength, does fit. Generating the appropriate $A_{2}$ photopigment curves from the nomogram of Ebrey and Honig (1977), and using the least-squares technique described by Thorpe (1972), yields weighting factors for the red, green and blue pigments of $0.80,0.31$ and -0.06 , respectively. This curve is shown in Fig. 4.

\section{Relation to electrophysiology}

The spectral sensitivity reported here closely matches the measurements of Regan et al. (1975), who recorded both ERG and tectal evoked response in

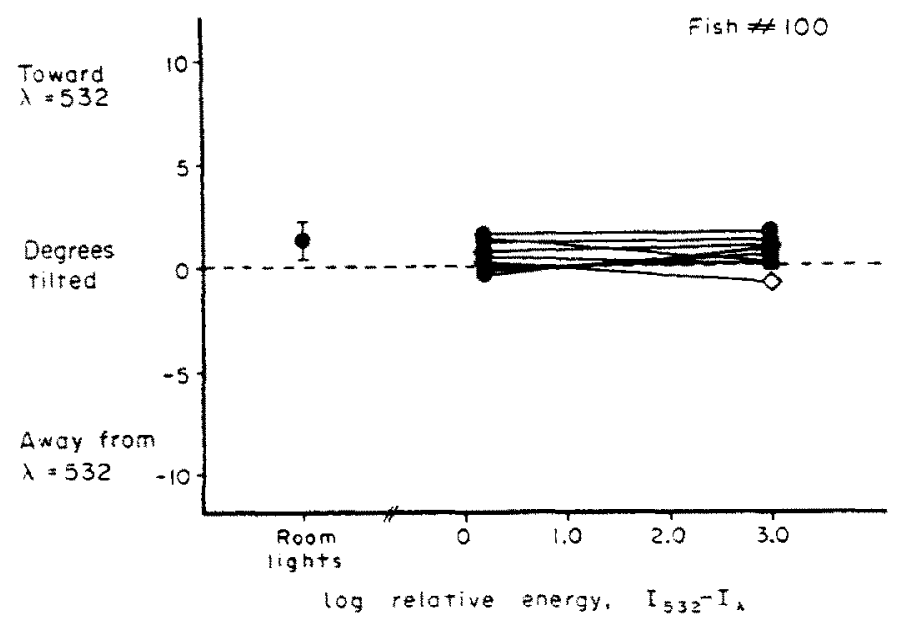

Fig. 3. DLR of a blind fish. Axes and symbols as in Fig. 2, except the filled circle on the left is the mean $( \pm 1$ S.E.M.) of 30 measurements. Standard errors around the unmarked points $(15$ measurements each) averaged \pm 0.58 
Table 1. Parametric comparison of photopic behavioral spectral sensitivity studies in the goldfish

\begin{tabular}{|c|c|c|c|c|c|c|}
\hline Reference & Behavior & $\begin{array}{c}\text { Stimulus } \\
\text { size } \\
\text { (deg) }\end{array}$ & $\begin{array}{l}\text { Stimulus } \\
\text { shape }\end{array}$ & $\begin{array}{l}\text { Incident } \\
\text { direction }\end{array}$ & $\begin{array}{l}\text { Background } \\
\text { adaptation }\end{array}$ & $\begin{array}{c}\text { Maximum } \\
\text { sensitivity }(\mathrm{nm})^{\mathrm{a}}\end{array}$ \\
\hline This study & $\begin{array}{l}\text { Reflex } \\
\text { (DLR) }\end{array}$ & 150 & Square & $\begin{array}{l}\text { Approximately } \\
\text { normal to pupil }\end{array}$ & None & 600 \\
\hline $\begin{array}{l}\text { Cronly-Dillon and } \\
\text { Muntz. } 1965\end{array}$ & $\begin{array}{c}\text { Reflex } \\
\text { (optomotor) }\end{array}$ & $45^{\circ}$ & Stripes & Unknown & $\begin{array}{l}\text { Tungsten } \\
(0.41 \mathrm{ft}-\mathrm{c})\end{array}$ & 635 \\
\hline $\begin{array}{l}\text { Shefner and } \\
\text { Levine. } 1976\end{array}$ & $\begin{array}{l}\text { Conditioned } \\
\text { (classical) }\end{array}$ & 10 & Round & $\begin{array}{l}\text { Approximately } \\
\text { normal to pupil }\end{array}$ & $\begin{array}{l}\text { Tungsten } \\
(25 \mathrm{ft}-\mathrm{c})\end{array}$ & 630 \\
\hline $\begin{array}{l}\text { Beauchamp and } \\
\text { Rowe. } 1977\end{array}$ & $\begin{array}{l}\text { Conditioned } \\
\text { (classical) }\end{array}$ & 21.5 & Round & $30^{\circ}$ nasal & $\begin{array}{l}\text { Tungsten } \\
(16 \mathrm{ft}-\mathrm{c})\end{array}$ & 450 \\
\hline Yager, 1967 & $\begin{array}{l}\text { Conditioned } \\
\text { (operant) }\end{array}$ & $50^{d}$ & Rectangle & $\begin{array}{l}\text { From nasal } \\
\text { field }\end{array}$ & $\begin{array}{l}\text { Tungsten } \\
(100 \mathrm{ft}-\mathrm{c})\end{array}$ & 400 \\
\hline
\end{tabular}

Although all the curves except the one reported here are nonmonotonic, the wavelength of maximum sensitivity is a good indicator of their basic shapes. The reader is referred to the original articles for details.

b Stimuli, which were on continuously, were about $0.50 \mathrm{ft}-\mathrm{c}$.

' Between stripes.

d Estimated subtense at response position.

the goldfish (see Fig. 2 in Powers, 1976). When they applied an additive model of cone pigment interaction to their data, they obtained the best fit with a red:green:blue proportional input of $0.82: 0.22: 0.03$, respectively.

The DLR spectral sensitivity is also similar to Burkhardt's (1966) ERG spectral sensitivity, but the match is not perfect. He found $\lambda_{\max }$ at about $560 \mathrm{~nm}$, with a less severe dropoff in the blue and a steeper one in the red. However, the discrepancy is at most $0.5 \mathrm{log}$ units in the blue (at $\lambda=500 \mathrm{~nm}$ ) and (except for $\lambda=670 \mathrm{~nm}$ ) $0.1 \log$ units in the red. These differences could be due to an influence of the white adapting light to which his fish were exposed $10 \mathrm{~min}$ before recording began. The best-fitting additive curve he obtained was with red:green:blue proportions of about $0.52: 0.69: 0.12$, respectively.

\section{Relation to other behavioral measurements}

The spectral sensitivity reported here does not match other behavioral results very well. Some possible reasons for the differences appear in Table 1 , which lists several methodological parameters for each of five behavioral studies of photopic spectral sensitivity in the goldfish. The likelihood that each of these was responsible for the divergent results will be considered next.

Differences in stimulus size and shape can be rejected as determinants of spectral sensitivity, at least in these five studies. The largest and smallest stimuli both produce curves that peak in the long wavelengths, and the two round stimuli result in peaks at opposite ends of the spectrum.

Differences in the angle of incidence of stimuli on the retina have been suggested as a basis for differences in spectral sensitivity (Powers, 1977) according to the following argument. Cones are directionally sensitive, and the degree of sensitivity is a function of the physical dimensions of the receptor and the

\footnotetext{
${ }^{3}$ The argument assumes the stripes in the optomotor drum (Cronly-Dillon and Muntz, 1965) were often normal to the pupil.
}

light (review: Miller, 1976). In three of the five studies the stimuli were presented essentially normal to the plane of the pupil. ${ }^{3}$ All rays from such stimuli pass through the center of the lens and strike the receptors in a direction parallel to the long axis of each. In Yager's (1967) operant conditioning paradigm, on the other hand the fish saw the stimuli head on during the orienting response, so that a forced choice could be made between them. Rays from directly in front of the fish even those parallel to the plane of the pupil, can enter the eye because the spherical lens protrudes beyond the iris (Easter, Johns and Baumann, 1977). Such rays do not pass through the center of the lens, and are refracted differently from those that do. Hence these rays strike the receptors off-axis. If the number of such rays were significant, then those cones least sensitive to the direction of incidence might be expected to dominate the spectral sensitivity. The cones that contain blue pigment have shorter myoids and outer segments than those that contain red pigment (Stell and Harosi, 1976) so the blue-sensitive cones may be influenced less by the direction of incidence than the red-sensitive ones. Yager's (1967) high blue-sensitivity is in the direction predicted by this argument. However, the recent results of Beauchamp and Rowe (1977) make the hypothesis appear unikely. Their fist were restrained in a holder such that the stimulus entered the eye essentially normal to the plane of the pupil, yet their data also show heightened blue sensitivity.

Northmore and Muntz (1974) have observed a correlation between the nature of the behavioral response given by the rudd in different experiments and the shape of the resulting spectral sensitivity curves. Table 1 shows that a similar correlation might also exist in the goldfish. For example, the results of the DLR study most closely resemble those of CronlyDillon and Muntz (1965), who used the optomotor response. Both are reflex behaviors. Yager's (1967) experiment required a complex sequence of behayiors, none of which could be categorized as a refiex, and his spectral sensitivity curve is different from those generated using reflexive responses. And although the 
results of the two studies that used classical conditioning are not alike, their differences could be due to a difference in psychophysical testing procedures: Shefner and Levine (1976) decreased stimulus intensity until the fish no longer responded, while Beauchamp and Rowe (1977) increased stimulus intensity until a response occurred.

The shape of the spectral sensitivity curves also correlates with the background and adaptation conditions used. In general, the lower the background luminance, the longer $\dot{\lambda}_{\max }$. In the present study, the room was dark and the fish was required to match two monochromatic lights. The luminance of the monochromatic lights. however, was close to the luminance of the tungsten background used by Cronly-Dillon and Muntz (1965), whose spectral sensitivity curve is most similar to the one reported here. Although the background used by Beauchamp and Rowe (1977) was slightly dimmer than that used by Shefner and Levine (1976), it remained on during testing and may have been more effective as a consequence. The notion that luminance may affect behavioral measurements of spectral sensitivity in the goldfish is given some support by Yarczower and Bitterman (1965). They found latency to respond to blue targets tended to decrease with high target luminance. while latency to respond to longer wavelength targets remained about the same. This property could result in proportionately more responses to threshold blue stimuli in any task that involves responding within a time limit.

A final consideration regarding background and adaptation conditions is their chromaticity. Yager. who found high blue-sensitivity when his fish were adapted to a tungsten light (Yager, 1967), could mimic the effect of that adaptation by using a Wratten 26 (red) filter (Yager, 1969).

\section{CONCLUSION}

Measuring spectral sensitivity by means of a reflexive response has resulted in a function that is similar to massed electrophysiological responses from retina and tectum. The dissimilarities between the spectral sensitivity reported here and those determined using other, nonreflexive, behavioral techniques could be due to differences in (1) the nature of the background on which the stimuli were viewed or (2) the nature of the behavioral response required of the fish.

\section{Note added in proof}

A. R. Heath and H. G. Sperling (personal communication) have obtained preliminary data that support the conclusions of this paper. They used classical conditioning. and determined thresholds by decreasing stimulus intensity until the fish no longer responded. Stimuli were round and large (about $160^{\circ}$ ), and superimposed on a background that was spectrally flat $(+0.2 \mathrm{log}$ units) between 420 and $620 \mathrm{~nm}$ (tungsten-halogen source plus Bausch \& Lomb color-correction filter). The spectral sensitivity curves they obtained, although preliminary, are very similar in shape to the one shown here (Fig. 4).

Acknowledgements-This research was supported by graduate student research grants to M.K.P. from the Department of Psychology and the H. H. Rackham School of Graduate Studies, University of Michigan, and by PHS grant EY-00168 to S. S. Easter Jr. M.K.P. was supported by predoctoral fellowships from N.I.M.H. and the University of Michigan. I thank Dr Easter for his support and insightful comments, Dr A. M. Popper his help in identifying otoliths, and Drs M. Alpern. C. M. Cicerone, R. E. Davis, D. G. Green, P. R. Johns, R. W. Knighton, J. T. Schmidt and W. C. Stebbins for useful discussions at various stages of the work.

\section{REFERENCES}

Beauchamp R. D. and Rowe J. S. (1977) Goldfish spectral sensitivity: A conditioned heart rate measure in restrained or curarized fish. Vision Res. 17, 617-624.

Burkhardt D. A. (1966) The goldfish electroretinogram: Relation between photopic spectral sensitivity functions and cone absorption spectra. Vision Res. 6. 517-532.

Burkhardt D. A. (1968) Cone action spectra: Evidence from the goldfish electroretinogram. Vision Res. 8 . 839-853.

Cronly-Dillon J. R. and Muntz W. R. A. (1965) The spectral sensitivity of the goldfish and the clawed toad tadpole under photopic conditions. J. exp. Biol. 42. $481-494$.

Dartnall H. J. A. (1953) The interpretation of spectral sensitivity curves. Br. med. Bull. 9, 24-30.

Easter S. S. Jr. Johns P. R. and Baumann L. R. (1977) Growth of the adult goldfish eye. I. Optics. Vision Res. $17,469-477$.

Ebrey T. G. and Honig B. (1977) New wavelength dependent visual pigment nomograms. Vision Res. 17, 147-151.

Hárosi F. I. and MacNichol E. F. Jr (1974) Visual pigments of goldtish cones: Spectral properties and dichroism. $J$ gen. Physiol. 63, 279-304.

Holst E. von (1935) L ber den Lichtrukenreflex bei Fischen Publ. Sraz. Zool. Vapoli. 15. $1+3-158$.

Kaneko A. (1973) Receptive field organization of bipolar and amactine cells in the goldtish retina. J. Physiol. 235. 133-153.

Liebman P. A. and Entine G. (1964) sensitive low-lightlevel mictospectrophotometer: Detection of photosensitive pigments of retinal cones. $\delta$. opt. Soc. Am. 54 , 1451-1459.

Marc R. E. and Sperling H. G. (1976a) Color receptor identities of goldfish cones. Science 191, 487-489.

Marc R. E. and Sperling H. G. (1976b) The chromatic organization of the goldfish cone mosaic. Vision Res. $16,1211-1224$.

Marks W. B. (1965) Visual pigments of single goldfish cones. J. Physiol. 178, 14-32.

Miller W. H. (1976) Optical guiding by photoreceptor cells Fedn Proc. Fedn Am. Socs exp. Biol. 35, 37-43.

Northmore D. P. M. and Muntz W. R. A. (1974) Effects of stimulus size on spectral sensitivity in a fish (Scardinius erythrophthalmus), measured with a classical conditioning paradigm. Vision Res. 14, 503-514.

Pfeiffer W. (1964) Equilibrium orientation in fish. In International Review of General Experimental Zoology, Vol. 1 (edited by Felts W. J. L. and Harris R. J.) Academic Press, New York.

Powers M. K. (1976) Behaviorally measured spectral sensitivities of the goldfish match physiological predictions. Neurosci. Abstr. 2 1084.

Powers M. K. (1977) Visual sensitivity of the goldfish. PhD dissertation, University of Michigan.

Powers M. K. and Easter S. S. Ir (1978a) Absolute visual sensitivity of the goldfish. This issue, pp. 1137-1147.

Powers M. K. and Easter S. S. Je (1978b) Wavelength discrimination by the goldfish near absolute visual threshold. This issue, pp. 1149-1154.

Regan D., Schellart N. A. M., Spekrejjse H. and van den Berg T. J. T. P. (1975) Photometry in goldfish by electro- 
physiological recording: Comparison of criterion response method with heterochromatic flicker photometry. Vision Res, 15. 799-808.

Shefner J. M. and Levine M. W. (1976) A psychophysical demonstration of goldfish trichromacy. V'ision Res. 16. $671-673$.

Silver P. H. (1974) Photopic spectral sensitivity of the neon tetra (Paracheirodon innesi (Myers)) found by the use of a dorsal light reaction. Vision Res. 14. 329-334.

Stell W. K. and Harosi F. I. (1976) Cone structure and visual pigment content in the retina of the goldfish. Vision Res. 16. 647-657.

Thibault C. (1949) Action de la lumière blanche et monochromatique sur la posture des poissons téléostéens: utilisation de cette action pour l'étude de la vision. Archs. Sci. physiol. 3, 101-124.

Thorpe S. A. (1972) The effect of chromatic adaptation and temperature on the spectral sensitivity of the goldfish. Carassius auratus. PhD dissertation. Brown Univer sity.
Tomita T., Kaneko A. Murakami M. and Pautler E. L. (1967) Spectral response curves of single cones in the carp. Vision Res. 7, 519-531.

Wagner H. G.. MacNichot E. F. Ir and Wolbarsht $M$. L. (1960) The response properties of single ganglion cells in the goldfish retina. J. gen. Physiot 43, 45-62.

Witkovsky P. (1965) The spectral sensitivity of retinal ganglion cells in the carp. Vision Res. 5, 603-614.

Witkovsky P. Nelson J. and Ripps H. (1973) Action spectra and adaptation properties of carp photoreceptors. J. gen. Physiol. 61, 401-423.

Yager D. (1967) Behavioral measures and theoretical analysis of spectral sensitivity and spectral saturation in the goldfish, Carassius auratus. Vision Re's. 7, 707-727.

Yager D. (1969) Behavioral measures of spectral sensitivity in the goldfish following chromatic adaptation. Vision Res. 9, 179-186.

Yarczower M. and Bitterman M. E. (1965) Stimulus generalization in the goldfish. In Stimulus Generalization (edited by Mostofsky D. I.). Stanford University Press. 